\title{
AS RESOLUÇÕES DO CONSELHO DE SEGURANÇA DA ONU SOBRE A PROLIFERAÇÃO DE ARMAS NUCLEARES NA COREIA DO NORTE: DILEMAS ENTRE A SOBERANIA E A SEGURANÇA COLETIVA
}

\author{
Mônica Teresa Costa Sousa ${ }^{1}$ \\ Sahid Sekeff Simão Alencar ${ }^{2}$
}

Resumo: O artigo busca avaliar o equilíbrio de poder na ordem mundial, especialmente por meio da análise das Resoluções proferidas pelo Conselho de Segurança das Nações Unidas contra a proliferação de armas nucleares na Coreia do Norte. Embora o discurso legitimador daquela entidade advenha da garantia da paz e segurança internacionais, além da tutela de direitos humanos, $\mathrm{O}$ que se percebe é na verdade a tentativa de justificar e perpetuar a sistemática de poder determinada há mais de 50 (cinquenta) anos, quando da criação das Nações Unidas. A metodologia adotada para tanto foi a revisão bibliográfica e a análise documental.

Palavras-chave: Conselho de Segurança; Coreia do Norte; Armas Nucleares; Ordem Mundial; Equilíbrio de poder.

\section{RESOLUTIONS OF THE UN SECURITY COUNCIL ON NUCLEAR WEAPONS PROLIFERATION IN NORTH KOREA: DILEMMAS BETWEEN SOVEREIGNTY AND COLLECTIVE SECURITY}

\begin{abstract}
The article seeks to assess the balance of power in the world order, especially through the review of the UN Security Council Resolutions against the proliferation of nuclear weapons in North Korea. Although the legitimating discourse of that entity comes from the guarantee of international peace and security, beyond the protection of human rights, what is perceived is actually the attempt to justify and perpetuate the system of power determined more than 50 (fifty) years ago, when the creation of United Nations. The methodology adopted for this was the bibliographic review and the documentary analysis.
\end{abstract}

Keywords: United Nations Security Council; North Korea; Nuclear weapons; World Order; Power balance.

\footnotetext{
1 Doutora em Direito pela Universidade Federal de Santa Catarina (USFC). Professora Associada na Universidade Federal do Maranhão (UFMA). Professora Visitante na Universidade de Valencia (Bolsa CAPES PVEX 88881.170435/2018-01). Professora dos cursos de graduação em Direito e pós-graduação (mestrado) em Direito e Instituições do Sistema de Justiça (PPGDir) e Cultura e Sociedade (PGCult). Coordenadora do Núcleo de Estudos em Direito e Desenvolvimento (NEDID/UFMA).

${ }^{2}$ Mestrando em Direito e Instituições do Sistema de Justiça (Universidade Federal do Maranhão), sob a orientação da Profa. Dra. Mônica Teresa Costa Sousa.
} 


\section{INTRODUÇÃO}

O texto tem como objetivo apresentar uma análise das Resoluções proferidas pelo Conselho de Segurança da Organização das Nações Unidas (CS) contra a proliferação de armas nucleares pela Coreia do Norte, nos últimos 12 (doze) anos, ou seja, a partir do ano de 2006, data do primeiro teste nuclear promovido pelos norte coreanos, até os presentes dias, contudo sem adentrar no mérito do acordo traçado entre os Estados Unidos da América (EUA) e a Coreia do Norte em 12 de junho de 2018.

Antes de serem analisadas as 17 (dezessete) Resoluções promovidas pelo Conselho de Segurança, buscar-se-á compreender o principal instrumento normativo que rege a matéria no plano internacional: o Tratado de Não-Proliferação das Armas Nucleares (TNP). Apesar da Coreia do Norte não ser signatária do mesmo, esse será o principal substrato que o Conselho de Segurança recorrerá ao elaborar suas Resoluções sobre a temática. Buscar-se-á ainda compreender o histórico de elaboração desse Tratado, visto que o discurso envolvendo o receio de uma nova guerra mundial, incluindo-se os impactos devastadores na utilização de armamentos nucleares, perpetuar-se-á para a própria atuação do Conselho.

Os membros permanentes do Conselho herdaram a "missão" dos países Aliados, vencedores da Segunda Guerra Mundial, de preservar pelo equilíbrio de poder no plano mundial e tutela de direitos humanos. Apesar desse fim ser plenamente legítimo, advindo a legalidade da Carta da Organização das Nações Unidas (ONU), esse tem sido deturpado e gerado uma "guerra preventiva" contra "[...] um estado cujo poder relativo esteja crescendo de modo a ameaçar esse equilíbrio, ainda que ele não seja responsável por qualquer agressão cometida contra um membro da sociedade internacional." (BULL, 2002, p. 165-166).

Dentre tais Estados ameaçadores, encontra-se a Coreia do Norte e seu objetivo de consolidar-se como potência bélica, especialmente por meio de armas nucleares e misseis balísticos intercontinentais, situação inconcebível para o equilíbrio de poderes da região, segundo a visão do CS.

Após análise do histórico de Resoluções proferidas pelo CS, serão intentadas razões de Estado que justifiquem o comportamento dos dirigentes da Coreia do Norte, bem como refletem consequências que tais Resoluções acarretam tanto no âmbito interno da Coreia do Norte, como no contexto mundial. 


\section{AS RESOLUÇõES DO CONSELHO DE SEGURANÇA DA ONU SOBRE A PROLIFERAÇÃO DE ARMAS NUCLEARES NA COREIA DO NORTE: DILEMAS ENTRE A SOBERANIA E A \\ SEGURANÇA COLETIVA}

\section{CONTEXTUALIZAÇÃO HISTÓRICA DA QUESTÃo COREANA}

Historicamente, há grande instabilidade na península coreana, destacando-se que a região era governada pelo Império Coreano até ser anexada, em 1905, pelo Japão. Posteriormente, sob o cenário do término da Segunda Guerra Mundial, em 1945, foi dividida entre zonas de ocupação norte-americanas e soviéticas. Gradativamente, conturbações foram ocorrendo, quando em 1948, a Coréia do Norte recusou-se a participar da eleição que proporcionaria a criação de dois governos separados para as duas zonas de ocupação, processo que seria supervisionado pelas Nações Unidas. Tanto a Coréia do Norte como a do Sul reivindicavam soberania sobre a península inteira, levando-as à Guerra da Coréia, em 1950. A solução adveio por meio de um armistício assinado em 1953, contudo, frequentemente, desde então, a harmonia restringiu-se ao plano formal. ${ }^{3}$

A Coréia do Norte apresenta uma localização geográfica privilegiada: a maior parte da sua fronteira é com a República Popular da China e uma pequena parte ao norte com a Rússia, ao sul com a Coreia do Sul (ao longo da Zona Desmilitarizada da Coreia). A região possui um grande potencial comercial, principalmente no que diz respeito a transporte de cargas por navios cargueiros.

A tensão na península coreana agravou-se no dia 09 de outubro de 2006, quando o governo norte-coreano realizou o primeiro teste nuclear oficial do país, ignorando as recomendações internacionais para não realização (UN, 2006, p. 1). Segundo dados da Inteligência Nacional dos Estados Unidos, a bomba atingiu um rendimento inferior a 1 quiloton (Kt); após o teste, imediatamente relatórios de todo o mundo observaram magnitude sísmica entre 3,5 e 4,9 na Escala Richter (HUI, 2007, p. 119-120).

Em revide ao teste, embargos econômicos foram aplicados sucessivamente à Coréia do Norte pelo CS, com a intenção de que os testes não se repetissem, contudo sem êxito, tanto é que houve mais 5 (cinco) testes nucleares e de maiores proporções. Tal complacência do Conselho é compreendida, por um dos seus membros, a China, ser a principal parceira comercial da Coréia do Norte, importando desde minerais até petróleo, utilizando-se como justificativa o fato de temer pelo colapso da economia coreana.

3 O "Acordo de Armistício da Guerra Coreana" pode ser lido na íntegra no seguinte link: https://peacemaker.un.org/sites/peacemaker.un.org/files/KP\%2BKR_530727_AgreementConcerningMilitaryAr mistice.pdf. Acesso em 11 de julho de 2018. 
Em relatório datado de 2017, o Escritório da Secretaria de Defesa dos Estados Unidos da América expôs os meios pelos quais a Coreia do Norte tem burlado as restrições impostas pelo CS: tráficos em alto-mar por meio de navios com documentações falsas, envio de cargas para empresas de fachada, embalagens com rótulos falsos, como se destinados a subsistência do povo coreano, etc. (OFFICE OF THE SECRETARY OF DEFENSE, 2017, p. 23).

Se não bastasse o aumento do poderio bélico da Coreia do Norte, o Conselho teme a capacidade do regime de Pyongyang de exportar seu conhecimento no campo nuclear a Estados também violadoras de direitos humanos, como a Síria e o Irã.

De maneira clara a legalidade das Resoluções do Conselho de Segurança encontra-se embasada na Carta da ONU e em seu estatuto; quanto ao tema de tutela de direitos humanos frente às armas nucleares, o principal instrumento normativo internacional é o Tratado de Não Proliferação de Armas Nucleares (TNP). As Resoluções emitidas pelo CS, em objeção ao fortalecimento bélico nuclear da Coreia do Norte, alinharam sua linha argumentativa segundo os parâmetros do TNP, por isso a importância do seu estudo, antes de se adentrar no mérito daquelas.

\subsection{Sobre o Tratado de Não-proliferação de Armas Nucleares}

Próximo do fim da Segunda Guerra Mundial, os Estados Unidos, com o intuito de consolidar sua hegemonia no plano internacional, lançaram duas bombas nucleares nas cidades japonesas de Hiroshima e Nagasaki. Os efeitos dessas bombas foram tão marcantes, que logo o horror às armas nucleares instalou-se como preocupação legítima e importante à sociedade internacional. ${ }^{4}$ A capacidade destrutiva de cada uma delas foi usada pelos meios de comunicação para imprimir um sentimento de medo e de instabilidade junto ao delicado equilíbrio internacional pós-Guerra.

Os Aliados se aproveitaram desse discurso para fundamentar o TNP, devidamente assinado em 01 de julho de 1968, mas somente em vigor, no plano internacional, em 05 de março de 1970 (UNODA, 2018) $^{5}$. Em termos mais claros, os países que incentivaram a formulação desse tratado e também o ratificaram, para evitar conflitos futuros em que

\footnotetext{
${ }^{4}$ Nos dizeres do historiador Hobsbawn: "Jamais a face do globo e a vida humana foram tão drasticamente transformadas quanto na era que começou sob as nuvens do cogumelo de Hiroxima e Nagasaki" (HOBSBAWN, 1995, p.177).

${ }^{5}$ Atualmente, 191 Estados são signatários do TNP (UNODA, 2018).
} 


\title{
AS RESOLUÇõES DO CONSELHO DE SEGURANÇA DA ONU SOBRE A PROLIFERAÇÃO DE ARMAS NUCLEARES NA COREIA DO NORTE: DILEMAS ENTRE A SOBERANIA E A SEGURANÇA COLETIVA
}

usassem armamento nuclear, eram justamente os que possuíam armas nucleares: Estados Unidos, União Soviética e Inglaterra ${ }^{6}$. Desta forma, pode-se questionar, de maneira crítica e mesmo cética: os objetivos dos Aliados se resumiam a manter a paz, ou o verdadeiro interesse era o de monopolizar os artefatos nucleares?

O preâmbulo do TNP enumera razões da urgência da assinatura do Tratado com o fim de promoção da paz, todavia essas se contradizem com a postura das potências, demonstrando muito mais o interesse delas em manter o status quo no globo e evitar futuras guerras mundiais:

\begin{abstract}
Considerando a devastação que seria provocada em toda a humanidade por uma guerra nuclear e a consequente necessidade de envidar todos os esforços para evitar o perigo de tal guerra e tomar medidas para salvaguardar a segurança dos povos; acreditando que a proliferação de armas nucleares aumentaria seriamente o perigo da guerra nuclear [...]; declarando a sua intenção de conseguir, o mais rapidamente possível, a cessação da corrida armamentista nuclear e de tomar medidas eficazes no sentido do desarmamento nuclear; instando a cooperação de todos os Estados na consecução deste objetivo [...]; Lembrando que, de acordo com a Carta das Nações Unidas, os Estados devem abster-se em suas relações internacionais da ameaça ou uso da força contra a integridade territorial ou independência política de qualquer Estado, ou de qualquer outra maneira inconsistente com os Propósitos das Nações Unidas, e que o estabelecimento e a manutenção da paz e segurança internacionais devem ser promovidos com o mínimo de desvio para os armamentos dos recursos humanos e econômicos do mundo [...]. (TRADUÇÃO NOSSA). (UN, 1968, p. 169171).
\end{abstract}

Sob a mesma linha argumentativa crítica, Raymond Aron diverge da crença geral de que a produção de armamento nuclear era o motivo da instabilidade na Guerra Fria (período posterior a Segunda Guerra). O autor considerava que o porte deste tipo de artefato era o que garantia a estabilidade entre os países, pois era responsável pelo equilíbrio militar entre as grandes potências:

No nível mais elevado de abstração, a política de equilíbrio se reduz à manobra destinada a impedir que um Estado acumule forças superiores às de seus rivais coligados. Todo Estado se quiser salvaguardar o equilíbrio, tomará posição contra o Estado ou a coalizão que pareça capaz de manter tal superioridade. Esta é uma regra geral válida para todos os sistemas internacionais (ARON, 2002, p.193).

Se no Preâmbulo, um observador mais atento já questionava as verdadeiras intenções do Tratado, tal sutileza não se preservou ao longo dos artigos. Há uma nítida distinção entre os países detentores de armamentos nucleares, aos quais se destinam o art. $1^{\circ}$, e os que não os detém, enquadrados nos arts. $2^{\circ}, 3^{\circ}$ e $6^{\circ}$. Esse segundo grupo de países, ao aderirem ao

\footnotetext{
${ }^{6}$ Além desses três países, França e China também eram potências nucleares, contudo somente ratificaram o TNP em 1992 em virtude de divergências quanto ao conteúdo desse (UNODA, 2018).
} 
Tratado, se submeteriam a instrumentos de fiscalização promovidos pela Agência Internacional de Energia Atômica (AIEO), enquanto o primeiro grupo gozaria de ampla autonomia. Essa discriminação foi o principal motivo para que, nas décadas iniciais, não houvesse uma ampla adesão de Estados.

Ora, um Estado ao ratificar o TNP, simultaneamente em que colaboraria com princípios humanitários, base de um pretenso direito cosmopolita, atestaria a vulnerabilidade de sua soberania ante às superpotências. Essa constatação agravou-se nos anos posteriores à Segunda Guerra, visto que EUA e União Soviética, em sentido oposto ao preconizado no TNP, aumentaram exponencialmente o seu arsenal atômico, deflagrando a falência do Tratado. $^{7}$

A partir dessas considerações ao TNP, passar-se-á a apreciação das Resoluções emitidas pelo CS, como revide ao fortalecimento bélico nuclear da Coreia do Norte, nos últimos 12 (doze) anos, ou seja, a partir do ano de 2006 até os presentes dias, contudo sem adentrar no mérito do acordo traçado entre os EUA e a Coreia do Norte em 12 de junho de 2018.

\section{AS RESOLUÇÕES DO CONSELHO DE SEGURANÇA CONTRA A PROLIFERAÇÃO DE ARMAS NUCLEARES NA COREIA DO NORTE}

Considerando a importância das Resoluções do Conselho de Segurança das Nações Unidas e o impacto destes documentos na ordem internacional, tem-se neste tópico um breve relato sobre aquelas que dizem respeito à questão norte-coreana.

\subsection{Resoluções $\mathbf{n}^{\circ} .1718$ (2006) e 1874 (2009)}

Em 3 de outubro de 2006, o chefe do regime comunista da Coreia do Norte, Kim Jong-il utilizou-se da mídia para divulgar publicamente que sua nação tinha substrato para a realização de um teste nuclear, 6 (seis) dias depois esse foi realizado (Korean Central News Agency apud HUI, 2007, p. 128).

\footnotetext{
${ }^{7}$ A redução no arsenal atômico das duas maiores potências atômicas somente iniciou-se a partir de 1991 com o Strategic Arms Reduction Treaty (START), tratado bilateral que possibilitou a verificação das instalações reciprocamente. (U.S. Department of State).
} 


\section{AS RESOLUÇõES DO CONSELHO DE SEGURANÇA DA ONU SOBRE A PROLIFERAÇÃO DE ARMAS NUCLEARES NA COREIA DO NORTE: DILEMAS ENTRE A SOBERANIA E A SEGURANÇA COLETIVA}

Em retaliação, o CS, principalmente sob a influência do então presidente dos EUA, G. W. Bush, elaborou a Resolução n ${ }^{\circ}$. 1718, adotada no dia 14 de outubro de 2006. Faz-se necessária uma breve regressão ao atentado de 11 de setembro de 2001, o qual desencadeou a "Doutrina Bush" e a tipificação de alguns Estados como Rogue States, incluindo a Coreia do Norte, esses seriam os que:

Brutalizam seu próprio povo e desperdiçam seus recursos nacionais para o ganho pessoal dos governantes; Não demonstram respeito pelo direito internacional, ameaçam seus vizinhos e violam de maneira cruel os tratados internacionais dos quais são parte; Estão determinados a adquirir armas de destruição em massa, juntamente com outras tecnologias militares avançadas, para serem usadas como ameaças ou ofensivamente para alcançar os projetos agressivos desses regimes; Patrocinam o terrorismo em todo o mundo; Rejeitam os valores humanos básicos e odeiam os Estados Unidos e tudo o que ele defende." (TRADUÇÃO NOSSA). (THE NATIONAL SECURITY STRATEGY OF THE UNITED STATES OF AMERICA, 2002, p. 14).

A Resolução $n^{\circ}$. 1718 exigia que a Coreia do Norte não fizesse novos testes nucleares nem lançamentos de mísseis balísticos ( $\S \S 2^{\circ}$ e $\left.5^{\circ}\right)$; além de reincorporação ao TNP e as salvaguardas do AIEO $\left(\S \S 4^{\circ}\right.$ e $\left.6^{\circ}\right)$. Nesse último ponto, indaga-se a legitimidade do CS para impor a adesão de um Estado a um Tratado, ferindo o princípio basilar da autodeterminação dos povos, bem como contrariando as condições de validade de um tratado, vez que uma destas é o consentimento regular (ausência de coação). Como ápice da presente Resolução, foi imposto o seguinte embargo:

8. Decide que: a) Todos os Estados Membros devem impedir o fornecimento, a venda ou a transferência, direta ou indiretamente, para a República Popular Democrática da Coreia ${ }^{8}$, através dos seus territórios ou pelos seus nacionais, ou através da utilização de navios ou aeronaves que arvorem o seu pavilhão, quer sejam ou não provenientes do seu território, de: i. [...] Armas [...]; b) A República Popular Democrática da Coreia deve deixar de exportar todos os artigos referidos nas subalíneas i) e ii) da alínea a) supra e todos os Estados Membros devem proibir a aquisição à República Popular Democrática da Coreia de tais artigos pelos seus nacionais ou através da utilização de navios ou aeronaves que arvorem o seu pavilhão, quer estes sejam ou não provenientes do território da República Popular Democrática da Coreia; c) Todos os Estados Membros devem impedir quaisquer transferências para a República Popular Democrática da Coreia pelos seus nacionais ou a partir dos seus territórios, ou a partir da República Popular Democrática da Coreia pelos seus nacionais ou a partir do seu território, de formação técnica, aconselhamento, serviços ou assistência relativos ao fornecimento, fabrico, manutenção ou utilização dos artigos referidos nas subalíneas i) e ii) da alínea a) supra; [..] f) [...] todos os Estados Membros são instados a adotar, em conformidade com as suas autoridades e leis nacionais e com o direito internacional, medidas de cooperação nomeadamente a inspeção da carga com destino ou proveniente da República Popular Democrática da Coreia, conforme necessário. (UN, 2006, p. 2-3).

\footnotetext{
${ }^{8}$ Por vezes, as Resoluções abreviam nome do Estado "República Popular Democrática da Coreia" por DPRK, sigla em inglês, traduzida no presente texto por RPDC.
} 
Os embargos de armas e aportes financeiros foram acompanhados por restrições de acesso a tecnologias e equipamentos $(\S 12$, a), justamente com o intuito de impedir a fabricação de armas nucleares pelos norte-coreanos. Nesse momento inicial, os atos do CS indicavam um descrédito que a Coreia do Norte, em decorrência de seus escassos recursos financeiros, poderia impulsionar o seu arsenal bélico.

O CS fundamenta sua decisão na instauração do temor mundial diante de uma possível guerra nuclear, o que comprometeria o sistema de paz e segurança internacional conquistado, além de resgatar a ideologia da instabilidade, amplamente divulgada durante a Guerra Fria.

A ineficácia da Resolução $\mathrm{n}^{\circ} .1718$ e a inércia do CS em aplicar sanções mais condizentes para cessar o conflito, permitiu que o governo norte-coreano, no dia 25 de maio de 2009, realizasse um novo teste nuclear, de proporções maiores que o anterior (UN, 2009, p. 1).

O teste nuclear teve como mola propulsora as sanções econômicas impostas pelos EUA, além de ser uma demonstração da soberania interna da Coreia do Norte frente "a política hostil e viciosa" dos EUA, Japão e Coreia do Sul, de acordo com o governo nortecoreano. Diante dessa nova violação, que agitou outra vez os ânimos globais, o CS decretou outra Resolução, a de número 1874 (12 de junho de 2009).

A Resolução $n^{\circ}$. 1874 recepcionou as sanções anteriores, instalando um Grupo de Especialistas para fiscalização das sanções impostas na Resolução $n^{\circ} .1718$ (§ 26), além de acrescentar as seguintes recomendações:

11. Exorta todos os Estados a que inspecionem, em conformidade com sua legislação nacional e com as competências dela decorrentes, e em consonância com o direito internacional, todas as cargas destinadas à República Popular Democrática da Coreia, ou dela provenientes, que se encontrem em seus territórios, incluindo portos e aeroportos, na eventualidade de que o Estado em questão disponha de informações que forneçam bases razoáveis para se acreditar que a carga contenha itens cujo fornecimento, venda, transferência ou exportação esteja proibido nos parágrafos 8(a), 8(b) e 8(c) da Resolução 1718 ou nos parágrafos 9 ou 10 desta Resolução, com o propósito de assegurar a implementação estrita desses dispositivos; 12. Exorta todos os Estados Membros a que inspecionem embarcações em alto mar, com o consentimento do Estado de bandeira, na eventualidade de que o Estado em questão disponha de informações que forneçam bases razoáveis para se acreditar que a carga contenha itens cujo fornecimento, venda, transferência ou exportação esteja proibido pelos parágrafos 8(a), 8(b) e 8(c) da Resolução 1718 ou pelos parágrafos 9 ou 10 desta Resolução, com o propósito de assegurar a implementação estrita desses dispositivos; 13. Exorta todos os Estados a que cooperem com as inspeções realizadas ao amparo dos parágrafos 11 e 12, e, na eventualidade de que o Estado de bandeira não dê seu consentimento à realização da inspeção no alto mar, decide que o Estado de bandeira ordene que a embarcação seja 


\section{AS RESOLUÇõES DO CONSELHO DE SEGURANÇA DA ONU SOBRE A PROLIFERAÇÃO DE ARMAS NUCLEARES NA COREIA DO NORTE: DILEMAS ENTRE A SOBERANIA E A \\ SEGURANÇA COLETIVA}

levada a um porto apropriado e conveniente para que as autoridades locais realizem a inspeção exigida ao amparo do parágrafo 11. (UN, 2009, p. 3).

As sanções propostas por essa Resolução, mais uma vez foram ineficazes para a solução do conflito. O que aumentou ainda mais a instabilidade na região, retomando-se as "velhas rixas" existentes entre as duas Coreias. Houve sucessivas ameaças de ataques militares por parte da Coréia do Norte em relação a do Sul, um risco à permanência do armistício de 1953, o qual findou a Guerra das Coreias.

Os ânimos na região permaneceram exaltados mesmo com a morte do líder norte coreano, que deixou no poder seu filho, Kim Jong-Um. Tão logo assumiu, autorizou o lançamento de um foguete em 13 de abril de 2012; o artefato explodiu dois minutos após o lançamento, justificado pela Coreia do Norte com o propósito de colocar em órbita um satélite de uso civil. Porém, essa justificativa não foi aceita pelo CS, que entendeu que o lançamento significava uma grave violação às Resoluções $n^{\circ}$. 1718 e 1874. Desta feita, a China, aliada natural da Coreia do Norte, fez eco às queixas das demais potências mundiais, no sentido de apoiar novas sanções ao país, em caso de novas violações (ARMS CONTROL ASSOCIATION).

2.2. Resoluções $n^{\circ} .1928$ (2010), 1985 (2011), 2050 (2012), 2087 (2013) e 2094 (2013)

Diante de tantas questões envolvendo o governo norte-coreano, o CS viu-se limitado em seu campo de atuação, e recorrer ao hard power não era uma opção, fato evidenciado pelas Resoluções no 1928 (07 de junho de 2010), 1985 (10 de junho de 2011) e 2050 (12 de junho de 2012) prorrogarem sucessivamente os trabalhos do Grupo de Especialistas, enunciado no $\S 26$ da Resolução $n^{\circ}$. 1874, voltados a fiscalização das sanções preconizadas na Resolução $n^{\circ} .1718$.

Em 12 de dezembro de 2012, a Coreia do Norte realizou novo lançamento de mísseis balísticos. Diante das constantes críticas internacionais sobre o modo ineficaz que estava lidando com a questão, o Conselho decidiu agravar as sanções, destacando-se, nos $\S \S 7^{\circ}$ e $8^{\circ}$, a possibilidade dos países membros das Nações Unidas em trânsito poderem requisitar e destruir todo o equipamento presente em navios norte coreanos que se negassem a serem revistados; ampliaram-se os embargos financeiros a Coreia, contudo ressaltou-se, pela primeira vez, que não se buscava acarretar consequências humanitárias adversas a população civil (\$18). 
Em represália, a Coréia do Norte anunciou que revidaria com ataques militares os seus navios que fossem interceptados, além de não garantir a segurança dos navios estrangeiros no Mar Amarelo, importante rota comercial da região (DUNNE, 2013, p. 3842). ${ }^{9}$ Com o intuito de demonstrar sua ampla insatisfação, a Coreia do Norte realizou o terceiro teste nuclear no dia 12 de fevereiro de 2013. O Centro de Estudos Geológicos dos EUA identificou uma magnitude sísmica na ordem de 4,7. Por sua vez, pesquisadores americanos enfatizaram o avanço dos norte coreanos se comparado ao primeiro teste (NIKITIN, 2013, p. 14).

Seguindo uma lógica consequencialista de ação e reação, ante o terceiro teste nuclear o CS impôs a Resolução no. 2094, de 07 de março de 2013, objetivando isolar a Coreia do Norte de qualquer aporte financeiro. Nessa Resolução, logo em seu preâmbulo, há uma crítica de que a Coreia tinha "abusado" de suas prerrogativas e imunidades, conferidas pelas Convenções de Viena sobre Relações Diplomáticas e Consulares (UN, 2013b, p. 1), como se per $\mathrm{si}$, isso fosse a causa das burlas as sanções anteriores.

Semelhantemente a Resolução $\mathrm{n}^{\circ}$. 1718, existem constantes exigências de que a Coreia do Norte retorne ao TNP ( $\S 2^{\circ}$ e $3^{\circ}$ ), desprezando-se o elemento volitivo do Estado. Todos os demais parágrafos orientam-se pela ideia de evitar que os países produzam e armazenem armas nucleares, uma ameaça à paz e segurança internacional, objetivos maiores das Nações Unidas.

Havia inovações perante as prévias Resoluções $\left(\S \S 7^{\circ}, 8^{\circ}\right.$ e $\left.9^{\circ}\right)$ : tratava-se da proibição (além da produção, manutenção e exportação) de serviços de intermediação ou fornecimento a outros Estados. Isto é, proibiu-se a Coreia do Norte de qualquer tipo de atividade ligada a artefatos bélicos, seja essa relação de posse ou de produção, até mesmo de intermediação de venda. Definiu-se em seguida, que quaisquer entidades ou pessoas estavam igualmente proibidas de atuar em função da Coreia para atingir as finalidades bélicas que o país almejava (UN, 2013b, p. 2-3).

Apesar do interesse do CS não ser o de prejudicar a população civil, mas tão somente o de inviabilizar a produção e comercialização de material e armamento nuclear, isso tornouse bem difícil na prática. Segundo o $§ 10$, norte coreanos que viviam em outros Estados, caso seguissem instruções de uma ou mais pessoas, bem como de entidades vinculadas ao seu governo, deveriam ser expulsas e repatriadas ao seu país (UN, 2013b, p. 3). Apesar de

\footnotetext{
${ }^{9}$ Tal reação do governo norte coreano podia ser justificada tendo em vista que o país arrecada muitas divisas com a circulação de navios cargueiros.
} 


\title{
AS RESOLUÇõES DO CONSELHO DE SEGURANÇA DA ONU SOBRE A PROLIFERAÇÃO DE ARMAS NUCLEARES NA COREIA DO NORTE: DILEMAS ENTRE A SOBERANIA E A \\ SEGURANÇA COLETIVA
}

algumas poucas exceções, medidas como essa, somente agravariam a vulnerabilidade de cidadãos que sequer podem exprimir a sua real vontade, afinal residem sob uma ditadura.

Os $\S \S 16$ a 22 visavam selar todos os meios de escape dos produtos proibidos da Coreia do Norte. Assim, extinguiu-se a possibilidade de comércio de materiais para armamento nuclear, ou armamento nuclear em si, não sendo impedido à Coreia do Norte a manutenção de redes comerciais de importação e exportação (UN, 2013b, p. 4-5), contudo somente formalmente, haja vista que o objetivo aparente do CS era intensificar a miserabilidade da população para que se voltasse contra o seu governo. Tendo em vista que a legitimidade do CS se dá pela tutela dos direitos humanos, esses não poderiam usar os portadores de direitos como meios.

Aliás, o valor majoritariamente defendido nessa Resolução, que é a paz mundial, pode servir de instrumento de dominação, pois, com a divulgação da necessidade de manter a paz mundial, muitas ditaduras e situações de exploração podem ser defendidas. Nesse sentido,

\begin{abstract}
[...] valendo-se assim das 'opiniões geralmente aceitas' e amplamente partilhadas no imaginário social, o que permite aos grupos e classes dominantes nelas embutir os valores prevalecentes, a legitimidade implica um intrincado processo de adequação entre os pontos de vista particulares e o senso comum. Em virtude desse processo de ajuste das opiniões individuais aos repertórios de crenças generalizadas, através da retórica e pela utilização de um amplo catálogo de topoi, os regimes políticos e os sistemas legais tidos como legítimos constituem um universo simbólico em torno de certos lugares- comuns, como os de justiça ou bem estar, liberdade ou garantias individuais, fim social ou igualdade perante a lei, apelando para valores solidamente enraizados, de um lado, e de outro, disfarçam a natureza dos conflitos, individualizando-os e trivializando-os, ocultando suas origens históricas à medida que os trazem para o plano das conceitualizações, abstrações, generalizações e tipificações do universo jurídico (FARIA, 1988, p.108).
\end{abstract}

Um ponto curioso da Resolução no 2094 é o de ter ampliado a lista de artigos de luxo proibidos de comercialização com a Coreia do Norte, conforme se infere do Anexo IV: joias, iates e carros de luxo. Essa proibição remete-se ao $\S 8^{\circ}$, iii, da Resolução $n^{\circ}$. 1718, destinada a incomodar as elites do país, vinculadas ao Partido do Governo. Todavia, indaga-se qual o impacto efetivo dessa medida na não proliferação de armas nucleares.

\subsection{Resoluções no ${ }^{0} 2141$ (2014), 2207 (2015), 2270 (2016), 2276 (2016) e 2321 (2016)}

Mais uma vez a política não bem-sucedida do CS, mesmo após quase uma década, evidenciou-se nas Resoluções nº. 2141 (05 de março de 2014), 2207 (04 de março de 2015) e 
2276 (24 de março de 2016), restritas a prorrogações dos mandatos do Grupo de Especialistas, enunciado no § 26 da Resolução nº 1874.

Como revide aos embargos econômicos ao seu país, a Coreia do Norte promoveu, em 06 de janeiro de 2016, o quarto teste nuclear. Interessante se notar que os norte coreanos buscavam utilizar-se da mesma ideologia que reinou durante a confecção do TNP, tanto que as autoridades desse país alegaram na época que fora detonado, pela primeira vez, uma bomba de hidrogênio. Contudo, a Organização do Tratado de Proibição Completa de Testes Nucleares (CTBTO), por meio de análises dos impactos sísmicos, concluiu que dificilmente se tratava de uma bomba daquela natureza (ARMS CONTROL ASSOCIATION, 2018).

Em reação, o CS aprovou, em 02 de março de 2016, a Resolução no. 2270. Nitidamente, havia uma preocupação do cerceamento do governo norte coreano não somente ao acesso a tecnologias bélicas, como também, aeronáuticas e aeroespaciais ( $\S 5^{\circ}$ e 17 ). Ademais, intensificou-se o embargo financeiro, incluindo-se um controle sistemático de todas as cargas procedentes ou destinadas à Coreia do Norte; nessa esteira, as exportações de carvão, ferro e minério de ferro foram proibidas, exceto se os montantes gerados fossem destinados à subsistência da população civil (\$ 29). Ainda quanto as proibições de recursos minerais, incluíram-se ouro, titânio, vanádio e outros raros ( $\$ 30)$, possivelmente por serem usados em equipamentos altamente tecnológicos.

Reconhecendo uma fragilidade, a Resolução $n^{\circ}$. 2270, em seu § 16, admitiu o modo como a Coreia do Norte burlava as sanções. Ela o fazia por meio de "empresas fantasmas" e joint ventures, contudo o CS somente transferiu a responsabilidade para solução desse problema a um Grupo de Especialistas, o qual teve seu mandato prorrogado por meio da Resolução no. 2276 (24 de março de 2016).

Decorridos aproximadamente mais 7 (sete) meses, em 09 de setembro de 2016, houve o quinto teste nuclear, no qual se registraram atividades sísmicas na magnitude de 5,0 (ARMS CONTROL ASSOCIATION). Em contrapartida, foi aprovada a Resolução n 2321 em 30 de novembro de 2011, particularizando-se somente por fixar o máximo de exportações de carvão, ferro e minério de ferro que a Coreia do Norte poderia fazer, bem como o montante financeiro resultante $(\S 26)$. 


\section{AS RESOLUÇõES DO CONSELHO DE SEGURANÇA DA ONU SOBRE A PROLIFERAÇÃO DE ARMAS NUCLEARES NA COREIA DO NORTE: DILEMAS ENTRE A SOBERANIA E A \\ SEGURANÇA COLETIVA}

\subsection{Resoluções no 2345 (2017), 2356 (2017), 2371 (2017), 2375 (2017), 2397 (2017) e 2407 (2018)}

No ano de 2017, o Conselho de Segurança aprovou uma série de Resoluções, mais especificadamente 5 (cinco), com o fim de reforçar os embargos à Coreia do Norte. A primeira delas, a Resolução $n^{\circ}$. 2345, aprovada em 23 de março de 2017, destinou-se a prorrogar o mandato do Grupo de Especialistas que auxiliava o CS. Decorrido pouco tempo, em 02 de junho de 2017, foi aprovada a Resolução $n^{\circ}$. 2356, focada em ampliar a proibição de viagens de pessoas estratégicas ao governo norte coreano, bem como o congelamento de ativos financeiros dessas e de outras empresas (Anexos I e II).

A terceira Resolução, a de $n^{\circ}$. 2371, aprovada em 05 de agosto, reiterou todo o conteúdo das anteriores, acrescentando a proibição da compra de produtos pesqueiros advindos da Coreia do Norte (§9). Ademais, havia uma preocupação com norte coreanos que trabalham em outros Estados e direcionam aportes financeiros ao seu país de origem $(\S 11)$ e formalizou-se, junto à Organização Internacional de Polícia Criminal (INTERPOL), notificações expressas sobre uma lista de norte coreanos estratégicos ao seu país ( $§ 23)$.

Em 03 de setembro, ocorreu o mais recente teste nuclear norte coreano, o mais poderoso até então. Com base nos dados sísmicos medidos pela CTBTO, vários especialistas avaliaram que o dispositivo tinha um rendimento explosivo superior a 100 quilotons, o que foi, no mínimo, 10 vezes superior ao teste nuclear anterior. A alegação da Coreia do Norte de que o dispositivo era uma bomba de hidrogênio, novamente não pôde ser confirmada, mas especialistas duvidaram. A estimativa sísmica da CTBTO foi estimada, após reanálise, em 6,1 (ARMS CONTROL ASSOCIATION, 2018).

Contraditoriamente, após 11 anos de sanções impostas pelo Conselho de Segurança à Coreia do Norte, não somente não foi alcançado o objetivo de impedir a confecção de armamentos bélicos por aquele país, como foram exponencialmente aprimorados. A Coreia do Norte tem questionado não somente a lógica de poder imposta pelo Conselho, como indiretamente tem feito outros Estados a fazerem o mesmo. ${ }^{10}$

\footnotetext{
${ }^{10}$ A título elucidativo, cita-se a ação intentada pelas Ilhas Marshall perante a Corte Internacional de Justiça (CIJ), em 24 de abril de 2014, contra os 9 (nove) Estados detentores de armas nucleares: China, Índia, Coréia do Norte, França, Israel, Paquistão, Rússia, Reino Unido e os Estados Unidos da América. O Estado autor alegou que todos esses países não cumpriram as suas obrigações internacionais no tocante ao dever de realizar ou concluir negociações para efetivar o desarmamento nuclear. A petição destacou que, na verdade, esses países estavam expandindo o seu poderia nuclear ao invés de reduzi-lo. Apesar da relevância do caso, a CIJ arquivou o
} 
Como resposta ao sexto teste nuclear promovido pela Coreia do Norte, o CS aprovou a Resolução $\mathrm{n}^{\circ}$. 2375 em 11 de setembro. Concomitantemente, em que se ampliou a lista de produtos norte coreanos proibidos de serem comprados, foram incluídos produtos têxteis $(\S$ 16), bem como de limitação aos produtos refinados derivados do petróleo ( $§ 14)$, flexibilizouse a proibição de empresas conjuntas de outros Estados com a Coreia do Norte, restrito a parcerias com China e Rússia:

18. Decide que os Estados proibirão a abertura, a manutenção e as operações, por seus nacionais ou em seus territórios, de todos as empresas conjuntas ou entidades cooperativas, novas e existentes, com entidades ou pessoas da RPDC, atuem ou não para o Governo da RPDC ou em seu nome, [...], e decide que a presente disposição não se aplicará com respeito aos projetos da China e da RPDC de infraestruturas de energia hidroelétrica existentes e o projeto portuário e ferroviário Rajin-Khasan da Federação Russa e da RPDC com o único fim de exportar carvão de origem russa, segundo se autoriza no parágrafo 8 da Resolução 2371 (2017). (TRADUÇÃO NOSSA). (UN, 2017, p. 06).

A quinta Resolução do ano de 2017, a de $\mathrm{n}^{\circ}$. 2397, aprovada em 22 de dezembro, adveio em decorrência do lançamento de um míssil balístico pela Coreia do Norte em 28 de novembro (UN, 2017e, p. 01). Apesar do agravamento no embargo econômico em alguns pontos, chama-se a atenção pelo próprio Conselho externar como a Coreia tem burlado suas sanções, demonstrando o próprio fracasso na forma como tem conduzido a situação:

9. Observa com grande preocupação que a RPDC exporta ilegalmente carvão e outros artigos proibidos, utilizando práticas marítimas enganosas e obtém ilegalmente petróleo através de transferências entre navios, e decide que os EstadosMembros confiscarão, inspecionarão e congelarão (confiscarão) qualquer navio sujeito a sua jurisdição que se encontre em suas águas territoriais, se eles tiverem motivos razoáveis para acreditar que tenham se envolvido em atividades, ou no transporte de artigos, que tenham sido proibidos [...]. (UN, 2017e, p. 5).

13. Manifesta a sua preocupação pelo fato dos navios que arvoram pavilhão da RPDC ou controlados, fretados ou operados por esse país ignorarem intencionalmente o requisito de manter o seu sistema de identificação automática de forma a evitar o controle da aplicação de sanções impostas pelas Resoluções do Conselho de Segurança, apagando esses sistemas a fim de ocultar o registro completo de seus movimentos, e insta os Estados Membros a intensificar sua vigilância em relação aos navios envolvidos em atividades proibidas pelas Resoluções [...]. (UN, 2017e, p. 6).

Até a presente data, somente fora emitida a Resolução $n^{\circ}$. 2407, em 21 março, destinada à prorrogação do mandato do Grupo de Especialistas até 24 de abril de 2019. Com base nesse prazo, o próprio Conselho desconfia que possa solucionar esse impasse, assim como seus membros, em especial, os EUA.

processo sem análise do mérito, isso devido à falta de jurisdição no caso, que decorreu da inexistência de uma disputa entre as partes (ICJ, 2016). 


\section{AS RESOLUÇõES DO CONSELHO DE SEGURANÇA DA ONU SOBRE A PROLIFERAÇÃO DE ARMAS NUCLEARES NA COREIA DO NORTE: DILEMAS ENTRE A SOBERANIA E A \\ SEGURANÇA COLETIVA}

\section{AS RAZÕES DE ESTADO DA COREIA DO NORTE}

Mazzuoli reverbera que o direito de existência é o direito fundamental de todo Estado e dele decorrem todos os demais direitos estatais (MAZZUOLI, 2013, p. 533). Um desses direitos decorrentes do direito de existência é o direito de conservação e defesa, que compreende todas as medidas estatais necessárias a conservação e defesa do Estado, notadamente contra os perigos que possam comprometer a integridade estatal.

Ainda quanto ao direito de conservação, esse implica direitos necessários à garantia do Estado contra qualquer mal que esse possa vir a sofrer no futuro e à manutenção dos seus elementos constitutivos, como seu território e o seu povo, bem como a preservação de sua integridade jurídica e política, sem as quais é impossível garantir-se como pessoa jurídica de direitos das gentes (MAZZUOLI, 2013, p. 533).

Sob essa perspectiva, entende-se que a busca por armamentos nucleares e incentivos de estudos voltados à produção nuclear representam uma forma de a Coreia do Norte mostrarse forte ante países em seu entorno que já possuem tais artefatos, como, por exemplo, a China, que há anos já possui esta tecnologia, e também seu maior inimigo, os EUA, detentores do incontestável poderio militar e que mantém soldados em sua proximidade.

Retrocede-se a obra clássica "O Príncipe", em que Maquiavel analisa a vulnerabilidade de uma nação caso não esteja armada, comportando-se até mesmo como uma ignomínia:

\footnotetext{
Porque não há nada de proporcionar entre armados e desarmados; e não é razoável que aquele que esteja armado deva obediência voluntariamente àquele que está desarmado, ou que o homem desarmado deva estar seguro entre os servos armados. Havendo desprezo por parte de um e suspeita por parte de outro, não é possível trabalharem bem juntos.

Assim, se um príncipe não entende a arte da guerra, além dos outros infortúnios já mencionados, não consegue ser respeitado por seus soldados, nem pode confiar neles. O príncipe nunca deve, portanto, desviar seus pensamentos do assunto da guerra, e em paz ele deve se dedicar mais ao seu exercício do que na guerra; ele pode fazer de duas formas: pela ação e pelo estudo. (MAQUIAVEL, 2009, p.70-71).
}

Ademais, pontua-se que desde que a ONU foi fundada, apesar de apresentar como norte imprescindível a preservação da paz internacional, em muitas situações históricas, a organização concretizou decisões que resultaram apenas em efeitos positivos imediatos. A Coréia do Norte, desde 1953, ao fim da Guerra das Coreias por meio do armistício, busca crescimento econômico ao mesmo tempo que tenta impedir o avanço ocidental e capitalista por sobre o Estado coreano. 
A ditadura coreana compromete o bem-estar de sua população, vez que se torna inviável manter níveis de desenvolvimento humano razoáveis ao considerar que cerca de $15 \%$ de todo o PIB coreano é destinado à indústria armamentista. Além disso, os altos custos para manutenção de equipamentos bélicos de alta complexidade contrapõem-se a mais da metade da população que padece de uma grave insegurança alimentar e de assistência médica, juntamente com $41 \%$ (quarenta e um por cento) da população desnutrida (UN, 2017e, p. 7-8).

Paradoxalmente, tais argumentos que em primeiro momento seriam desfavoráveis à própria estabilidade do governo norte-coreano, manifestam-se como importantes elementos legitimadores da soberania do Estado norte coreano.

\section{CONSIDERAÇÕES FINAIS}

A análise realizada nas linhas acima visou demonstrar, que, ao menos em ideal, as Resoluções por meio de uma análise formal, estão de acordo com os critérios que a ONU tutela. É obvio que essa análise, por seu caráter formal, deixa de considerar as divergências geopolíticas e econômicas, e também as diferenças socioculturais. Não é por isso que elas perdem sua validade, pois estão inseridas em um contexto que abrange grande quantidade de Estados, tendo em vista o amplo apoio de suas decisões, pelos países-membros da ONU. Como Bobbio afirma:

Deve-se recordar que o mais forte argumento adotado pelos reacionários de todos os países contra os direitos do homem, particularmente contra os direitos sociais, não é a sua falta de fundamento, mas a sua inexequibilidade. Quando se trata de enunciálos, o acordo é obtido com relativa facilidade, independentemente do maior ou menor poder de convicção de seu fundamento absoluto; quando se trata de passar à ação, ainda que o fundamento seja inquestionável, começam as reservas e as oposições (BOBBIO, 2004, p.24-25).

Evidenciou-se o problema da juridicidade do próprio CS pela desconsideração dos interesses velados dos seus membros. Isto porque, embora o CS e, assim, a própria ONU, busquem manter e realizar decisões puramente jurídicas, os entes que a realizam são Estados e inevitavelmente possuem interesses políticos que vão além da busca pela paz e segurança internacionais.

Ao se analisar o TNP e seu histórico, assim como as Resoluções do CS quanto a temática de não proliferação de armas nucleares pela Coreia do Norte, teve-se a intenção de demonstrar que cada um desses acordos levantou mais problemas do que aqueles que tentaram resolver e, assim, ao contrário de solucioná-los, os inflamou. 


\title{
AS RESOLUÇõES DO CONSELHO DE SEGURANÇA DA ONU SOBRE A PROLIFERAÇÃO DE ARMAS NUCLEARES NA COREIA DO NORTE: DILEMAS ENTRE A SOBERANIA E A \\ SEGURANÇA COLETIVA
}

Como advertido por Aron, as ideias espalhadas pelos vitoriosos da Segunda Guerra de que a produção de armamentos nucleares era motivo da instabilidade total dos anos da Guerra Fria podem ser falseadas. Isto porque:

\begin{abstract}
Em um mundo em que a força motriz resulta da aspiração das nações soberanas por poder, a paz só poderá ser mantida por meio de dois instrumentos". O primeiro é o mecanismo auto-regulador das forças sociais, que se manifesta sob a forma de luta em busca do poder na cena internacional, isto é, o equilíbrio de poder. O outro consiste nas limitações normativas dessa luta, sob a roupagem do direito internacional, da moralidade internacional e da opinião pública mundial (ARON, 2002, p.193).
\end{abstract}

Ora, por mais ideais que sejam as Resoluções do CS, é impossível que essas não impliquem consequências políticas, econômicas e sociais que não foram planejadas. Isso porque, por mais bem-intencionadas que sejam as atividades do CS, tal entidade não consegue suprir as discrepâncias socioeconômicas dos países membros, o que, necessariamente, leva à discussão de vários problemas; dentre eles destacam-se os que sempre aparecem relativos à questão da soberania do Estado e os de má compreensão (proposital ou não) das Resoluções por líderes políticos e pelos meios de comunicação.

Conclui-se que as Resoluções do CS permitem a continuidade de um código de equilíbrio de poder entre potências nucleares já fortemente armadas, ao mesmo tempo que inviabiliza a chegada de novos atores nesse delicado sistema de manutenção e compartilhamento de poder junto à sociedade internacional. O temor de uma guerra nuclear de proporções mundiais é real, e de fato as potências nucleares não se utilizam desse tipo de armamento em conflitos armados, mas sabe-se que a manutenção de arsenais nucleares serve muito mais à supremacia que vem mantendo viva a célebre afirmação de Raymond Aron, vez que vivemos sob uma "guerra improvável e uma paz impossível."

\section{REFERÊNCIAS}

ARMS CONTROL ASSOCIATION. Chronology of U.S.-North Korean Nuclear and Missile Diplomacy. Disponível em: https://www.armscontrol.org/factsheets/dprkchron. Acesso em: 11 de julho de 2018.

ARON, R. Paz e Guerra entre as nações. São Paulo: Imprensa Oficial do Estado de SP, 2002.

BOBBIO, N. A Era dos Direitos. Rio de Janeiro: Campus, 2004.

BULL, Hedley. A sociedade anárquica. Tradução de Sérgio Bath. Brasília: UnB/IPRI, 2002. 
DUNNE, Aaron. The Proliferation Security Initiative. Legal Considerations and Operational Realities. SIPRI Policy Paper, n. 36, may 2013.

FARIA, J. E. Eficácia jurídica e violência simbólica. São Paulo: EDUSP, 1988.

HOBSBAWN, E. A Era dos Extremos. São Paulo: Companhia das Letras, 1995.

HUI, Zhang. Revisiting North Korea's Nuclear Test. China Security, vol. 3, n. 3 Summer 2007, pp. 119-130.

ICJ - INTERNATIONAL COURT OF JUSTICE. Obligations concerning Negotiations relating to Cessation of the Nuclear Arms Race and to Nuclear Disarmament (Marshall Islands v. India), Jurisdiction and Admissibility, Judgment, I.C.J. Reports 2016.

MAQUIAVEL, N. O Príncipe. São Paulo: Universo dos livros, 2009.

MAZZUOLI, V. O. Curso de Direito Internacional Público. São Paulo: Revista dos Tribunais, 2013.

NIKITIN, Mary Beth. North Korea's Nuclear Weapons: Technical Issues. Congressional Research Service. Disponível em: https://fas.org/sgp/crs/nuke/RL34256.pdf. Acesso em 12 de julho de 2018.

OFFICE OF THE SECRETARY OF DEFENSE OF THE UNITED STATES OF AMERICA. Military and Security Developments Involving the Democratic People's Republic of Korea 2017. Disponível em: https://fas.org/irp/world/dprk/dod-2017.pdf. Acesso em em 11 de julho de 2018.

THE NATIONAL SECURITY STRATEGY OF THE UNITED STATES OF AMERICA. September 2002, 2002. Disponível em: https://www.state.gov/documents/organization/63562.pdf. Acesso em 10 de julho de 2018.

UN - UNITED NATIONS. Agreement between the Commander-in-Chief, United Nations Command, on the one hand, and the Supreme Commander of the Korean People's Army and the Commander of the Chinese people's volunteers, on the other hand, concerning a military armistice in Korea, 1953. Disponível em: https://peacemaker.un.org/sites/peacemaker.un.org/files/KP\%2BKR_530727_AgreementCon cerningMilitaryArmistice.pdf. Acesso em 11 de julho de 2018.

Treaty on the Non-Prolifération of Nuclear Weapons. Opened for signature at London, Moscow and Washington on 1 July 1968, 1968. Disponível em: https://treaties.un.org/doc/Publication/UNTS/Volume\%20729/volume-729-I-10485-

English.pdf. Acesso em 12 de julho de 2018.

Resolution $1718 \quad$ (2006), $2006 . \quad$ Disponível em: http://www.un.org/en/ga/search/view_doc.asp?symbol=S/RES/1718(2006). Acesso em 01 de julho de 2018. 


\section{Resolution $1874 \quad$ (2009), 2009. Disponível em:} http://www.un.org/en/ga/search/view_doc.asp?symbol=S/RES/1874(2009). Acesso em 01 de julho de 2018.

Resolution $1928 \quad$ (2010), 2010. Disponível em: http://www.un.org/en/ga/search/view_doc.asp?symbol=S/RES/1928(2010). Acesso em 01 de julho de 2018.

Resolution 1985 (2011), 2011. Disponível em: http://www.un.org/en/ga/search/view_doc.asp?symbol=S/RES/1985(2011). Acesso em 01 de julho de 2018.

Resolution 2050 (2012), 2012. Disponível em: http://www.un.org/en/ga/search/view_doc.asp?symbol=S/RES/2050(2012) . Acesso em 01 de julho de 2018.

Resolution 2087 (2013), 2013a. Disponível em: http://www.un.org/en/ga/search/view_doc.asp?symbol=S/RES/2087(2013). Acesso em 01 de julho de 2018.

Resolution 2094 (2013), 2013b. Disponível em: http://www.un.org/en/ga/search/view_doc.asp?symbol=S/RES/2094(2013). Acesso em 01 de julho de 2018.

Resolution 2141 (2014), 2014. Disponível em: http://www.un.org/en/ga/search/view_doc.asp?symbol=S/RES/2141(2014). Acesso em 01 de julho de 2018.

Resolution 2207

(2015),

2015.

Disponível

em:

http://undocs.org/S/RES/2207\%20(2015). Acesso em 01 de julho de 2018.

$$
\text { Resolution } 2270 \quad \text { (2016), 2016a. }
$$

Disponível

em: http://undocs.org/S/RES/2270(2016). Acesso em 01 de julho de 2018.

Resolution $2276 \quad$ (2016), 2016b.

Disponível

em:

http://undocs.org/S/RES/2276(2016). Acesso em 01 de julho de 2018.

Resolution $2321 \quad$ (2016), 2016c.

Disponível em:

http://undocs.org/S/RES/2321(2016). Acesso em 01 de julho de 2018.

$$
\text { Resolution } 2397 \quad \text { (2017), 2017a. }
$$

Disponível

em: http://undocs.org/S/RES/2397(2017). Acesso em 01 de julho de 2018.

Resolution $2345 \quad$ (2017), 2017b.

Disponível em: http://undocs.org/S/RES/2345(2017). Acesso em 01 de julho de 2018.

Resolution

2356

(2017),

2017c.

Disponível

em: http://undocs.org/S/RES/2356(2017). Acesso em 01 de julho de 2018. 
- Resolution 2371 (2017), 2017d. Disponível em: http://undocs.org/S/RES/2371(2017). Acesso em 01 de julho de 2018.

Resolution 2375 (2017), 2017e. Disponível em:

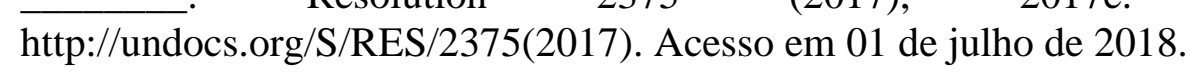

Resolution 2407 (2018), 2018. Disponível em: http://undocs.org/S/RES/2407(2018). Acesso em 01 de julho de 2018.

UNODA - United Nations Office for Disarmament Affairs. Treaty on the Non-Proliferation of Nuclear Weapons. Disponível em: http://disarmament.un.org/treaties/t/npt. Acesso em: 12 de julho de 2018.

U.S. DEPARTMENT OF STATE. Strategic Arms Reduction Treaties, 1991 and 1993. Disponível em: https://2001-2009.state.gov/r/pa/ho/time/pcw/104210.htm. Acesso em 12 de julho de 2018. 